\section{Resumo}

Este trabalho apresenta, analisa e discute os dados de 371 pareceres pedagógicos e 105 entrevistas com professores sobre como eles posicionam os alunos que apresentam dificuldade de aprendizagem. Entre tais alunos, observouse que é feita uma distinção entre aqueles considerados alunos problemas e os considerados alunos com deficiência. Entre os alunos problema, estão os que possuem diagnóstico médico de Transtorno de Déficit de Atenção e Hiperatividade (TDAH) ou que, segundo os professores, têm os sintomas desse transtorno e os que apresentam problemas de aprendizagem. Entre os alunos com deficiência, estão os que apresentam deficiência sensorial, cognitiva ou física. Todos eles são posicionados pelos professores como alunos de inclusão. As posições de aluno problema, aluno com deficiência e de aluno de inclusão, são construídas a partir de fronteiras imaginárias que separam o aprendente do não-aprendente, o aluno médio do aluno insuficiente, a corrigibilidade da incorrigibilidade, o incluído do excluído, etc. Problematizando esses enunciados e outras questões que se relacionam ao tema inclusão escolar, o trabalho traz alguns excertos dos materiais da pesquisa para dar materialidade à idéia de invenção de tipos específicos de alunos e de posições necessárias ocupadas por eles no currículo escolar.

\section{Palavras-Chave}

Inclusão escolar, alunos com deficiência, aluno problema, currículo escolar, dificuldade da aprendizagem

\section{Abstract}

This paper reports, analyses and discusses data from 371 pedagogical evaluations and 105 interviews with teachers about schoolchildren with learning difficulties. The professors divide the students in two groups: the problematic and the disabled. Among the problematic pupils, there are those with medical diagnosis of AttentionDeficit Hyperactivity Disorder (ADHD) or those, according to teachers, with the same symptoms and those with learning problems. Teachers put all of them in the category of inclusive schoolchildren. The labels of problematic, disabled and inclusive schoolchildren are built from imaginary boundaries that differenciate the schoolchild that learns from the schoolchild that does not learn, the average from the defficient, the included from the excluded, the corrigibility from the incorrigibility. Discussing these results and others questions about inclusive schooling, this paper transcribes various evaluations and interviews to show the character of invention of the positions attributed to the schoolchildren in the curriculum.

\section{Key words}

Inclusive schooling, problematic schoolchildren, disabled schoolchildren, inclusive schoolchildren, curriculum, learning difficulties 


\title{
In/exclusão escolar: a invenção de tipos específicos de alunos ${ }^{1}$
}

\author{
Maura Corcini Lopes ${ }^{2}$
}

\begin{abstract}
Agora, mais um risco: como deixar claro que uma hipercrítica a tais políticas de inclusão não implica, em absoluto, uma negação a elas, não implica uma recusa à própria inclusão? (Veiga-Neto, 2001, p. 109).
\end{abstract}

Abordar o tema da inclusão escolar já seria suficientemente desafiador, principalmente tentando articulá-lo à exclusão. Mais desafiador ainda se torna a tarefa de pensá-lo dentro de uma complexa rede de conceitos e práticas que constituem não só a visão de professores e da comunidade escolar sobre a inclusão, como também a visão dos próprios alunos apontados como sendo alunos de inclusão. O presente artigo nasce da necessidade de analisar e problematizar dados de uma pesquisa realizada por um grupo de pesquisadoras que integram do Grupo de Estudo e Pesquisa em Inclusão (GEPI). O grupo, sediado na Universidade do Vale do Rio dos Sinos (UNISINOS), é formado por professoras doutoras em Educação, mestrandas, doutorandas e bolsistas de iniciação científica. A UNISINOS é uma universidade brasileira, localizada no Estado do Rio Grande do Sul, mais especificamente, na cidade de São Leopoldo. Para esta análise, foi preciso selecionar partes de uma pesquisa maior, realizada através de uma ação conjunta entre um dos serviços que compõem o Programa de Educação e Ação Social (EDUCAS) e os pesquisadores do Grupo de Estudo e Pesquisa em Inclusão (GEPI) do Programa de Pós-Graduação em Educação da Universidade do Vale do Rio dos Sinos (UNISINOS).

Os professores e estagiários de Pedagogia e Psicologia que atuam no EDUCAS vêm trabalhando com crianças e jovens ditos com dificuldade de aprendizagem en-

\footnotetext{
${ }^{1}$ Texto recibido el 29 de enero, evaluado el 24 de abril y el 6 mayo, y arbitrado el 9 de junio de 2008.

2 Doutora em Educação. Professora da Universidade do Vale do Rio dos Sinos (UNISINOS), atuando no Programa de Pós-Graduação em Educação (PPGEdu). Coordenadora do Grupo Interinstitucional de Pesquisa em Educação de Surdos (GIPES/CNPQ). Coordenadora do Grupo de Estudos e Pesquisa em Inclusão (GEPI/UNISINOS). maura@unisinos.br
} 
caminhados das escolas públicas da cidade de São Leopoldo, bem como com as próprias escolas que encaminham alunos para atendimento já há 16 anos. Os pesquisadores do GEPI, desde o surgimento do grupo há seis anos, realizam parte de suas investigações utilizando o grande número de materiais que estão arquivados no EDUCAS e produzindo outros materiais junto aos alunos, professores e escolas onde o EDUCAS e a pesquisa estão colocados.

A pesquisa que apresento neste artigo analisou 371 encaminhamentos de alunos narrados por seus professores como tendo dificuldade de aprendizagem e 105 entrevistas com professores sobre como eles vêem tais alunos e a inclusão escolar. No conjunto dos materiais, observa-se que é considerado de inclusão qualquer aluno que apresente dificuldades de aprendizagem mais permanentes. Sob a dificuldade de aprendizagem, estão tanto aqueles que são colocados como alunos problemas quanto os colocados como alunos com deficiência.

Entre os nomeados como alunos problemas, estão aqueles que possuem, além da dificuldade de aprendizagem, diagnóstico médico de Transtorno de Déficit de Atenção e Hiperatividade (TDAH) ou que, segundo os professores, apresentam sintomas de TDAH. Considerando os 16 anos do EDUCAS, somente a partir de 2000 começam a aparecer documentos que nomeiam os ditos alunos com TDAH. Antes de tal aparição, já nomeada na década de 1990, os que hoje apresentam TDAH possivelmente eram narrados como indisciplinados, mal educados, sem limites, agitados, desatentos, etc. Não se observava a presença do diagnóstico TDAH definindo tipos de alunos que hoje são encaminhados para serviços de apoio pedagógico.

A dificuldade de aprendizagem, no entanto, é um dos sintomas e, às vezes, um dos diagnósticos mais antigos citados em anamneses e em pareceres pedagógicos. Embora a presença da Dificuldade de Aprendizagem seja notadamente a mais antiga entre o que vemos circular hoje nas escolas, a pouca clareza de informações sobre o que a define e os elementos que estão presentes na sua definição chamam a atenção dos pesquisadores. Poucos são os casos em que a Dificuldade de Aprendizagem aparece associada à dislalia e à dislexia. Dos 317 pareceres analisados, em mais de $70 \%$ são apontadas questões comportamentais e de indisciplina como causa da nãoaprendizagem dos alunos, sendo que a maior parte dos casos envolve meninos. A não-aprendizagem possui causas variadas, mas, independentemente delas, os alunos colocados como tendo dificuldade ou como não-aprendentes são vistos pelos professores como problemas para a escola. Interessante observar que, diferentemente dos tidos como problemas, estão alunos que possuem alguma deficiência sensorial, cognitiva ou física.

Nas entrevistas realizadas com os professores, é recorrente a reclamação sobre o comportamento dos alunos. Posicionados como sendo alunos de inclusão, estão tanto aqueles narrados como problemas (os que apresentam TDAH, indisciplina, com dificuldade de aprendizagem), quanto os narrados como possuidores de alguma deficiência. Entretanto, mesmo surpreendendo os pesquisadores, as situações de alunos com deficiência não são as mais citadas pelos professores como um desafio 
para eles. Geralmente, alunos com deficiência são narrados como queridos, amáveis, dóceis, carinhosos, que estão na turma para se socializarem, etc. A aprendizagem de conteúdos pelos alunos com deficiência não parece ser uma prioridade para muitos professores, pois, ao serem questionados sobre o desenvolvimento e a aprendizagem desses alunos, referem-se quase unicamente aos comportamentos e à autonomia conquistada por eles.

Diante do quadro apresentado a partir de uma primeira distribuição e organização dos materiais da pesquisa, vale frisar o objetivo deste trabalho: analisar e problematizar discursos que posicionam e nomeiam alunos que apresentam dificuldade de aprendizagem como sendo alunos problemas e alunos com deficiência - e ambos como sendo alunos de inclusão. Os alunos de inclusão são citados nos materiais como "os" diferentes, "os" problemáticos, "os" indisciplinados, "os" perturbados emocionalmente, "os" desatentos, "os" hiperativos, "os" com TDAH, "os" esforçados, "os" perdidos, "os" desajustados, "os" que não aprendem, entre outros marcadores que, quando atribuídos aos alunos, os inscrevem como indivíduos a corrigir.

Diante de uma demanda tão variada de casos de alunos que apresentavam dificuldade de aprendizagem para o EDUCAS, é possível visualizar as muitas dificuldades enfrentadas pela escola em trabalhar para normalizar os sujeitos não enquadrados em categorias predefinidas como sendo normais para o desenvolvimento. As escolas vivenciam a tensão da diferença e a tensão tempo escolar versus tempo de aprendizagem, de forma a produzir a diferença como algo indesejado e o tempo da aprendizagem como tempo escolar de aprendizagem. Na tentativa de unificação e enquadramento, aqueles mais resistentes são vistos como problemas que necessitam de atendimento especializado para que sejam normalizados. Nessa lógica, a diferença é narrada como sinônimo de deficiência, de indisciplina que pode ser tratada por pedagogias disciplinares e corretivas.

Quem está em posição de determinar quem são os diferentes são aqueles que se encontram dentro do que podemos denominar de zona de normalidade. Definir zona de normalidade torna-se tão difícil quanto definir o aluno que ocupa essa zona. A partir da invenção do nível de aproveitamento, do nível de desenvolvimento cronológico e cognitivo, combinado com respostas escolares, e de traços comportamentais que implicam ser disciplinado, saber conversar, ser solidário e dedicado aos estudos, etc., produz-se a figura daquele que serve como medida para avaliar todos - $\mathrm{o}$ aluno médio.

Quem é o aluno médio na escola? Essa pergunta poderia nos conduzir a um conjunto vazio, pois não há nenhum aluno que consiga chegar às exigências feitas para estar nessa posição, o que implica a necessidade de dedicação permanente para se atingir um tipo ideal, imaginário e, no limite, inatingível.

$\mathrm{Na}$ sombra do aluno médio, outras posições de aprendizagem são criadas. $\mathrm{Na}$ luta por ocupar outras posições, mas sem sair do espaço da escola dita comum, estão todos os alunos encaminhados aos serviços de apoio pedagógico. Tais serviços 
-criados para prover condições para que o projeto da inclusão e da escola para todos aconteça- funcionam como parte de uma maquinaria que tem, entre outras funções, a de manter a ordem e os alunos incluídos na escola comum. Manter-se junto na escola comum atende a um princípio legal segundo o qual todos devem, preferencialmente, estar na escola inclusiva. Tal princípio operante nessa lógica de normalização e de exclusão das diferenças dificulta que a inclusão -vista como o simples colocar para dentro de um mesmo espaço físico- seja um desencadeador de relações mais integradas, mesmo que essas sejam provisórias. Uma inclusão excludente é o que estamos observando nas escolas. No esquema velado de in/exclusão escolar, os serviços de apoio pedagógico parecem estar exercendo função primordial; são eles que criam condições para que os alunos permaneçam na escola em condições de acompanhar o tempo e a aprendizagem escolar e que, junto com um corpo de especialistas e a escola, atestam a incapacidade de o aluno acompanhar a escola comum.

Em outro texto, ao buscar a etimologia da palavra inclusão -enclausuramento, colocação dentro de um mesmo espaço físico (Lopes y Fabris, 2005)-, argumentei que a inclusão escolar, como é proclamada na Modernidade, é um projeto audacioso porque se coloca dentro de uma narrativa de transcendência e porque alimenta a compreensão da inclusão como lugar de chegada para todos. No entanto, o simples incluir em um mesmo espaço físico não garante a incorporação daquele que está sendo fisicamente incluído. Nessa lógica excludente da inclusão, está sendo contemplada a diversidade marcadamente visível no corpo dos sujeitos.

Estar excluído da escola passa pela experiência de estar dentro dela, lutando para compartilhar o espaço que foi criado para alguns que sempre estiveram (naturalmente) ali. Quero dizer que exclusão não significa somente ou simplesmente estar fora de espaços determinados como sendo bom para todos. Significa, também, estar dentro de tais espaços sendo narrado por expert, pela família e pelos professores como sujeito que apresenta sintomas que podem sugerir problemas de ordem física, sensorial, mental, afetiva, entre outros.

Ao afirmar que inclusão e exclusão não são nem estão em oposição, isso significa que elas são articuladas e inventadas juntas -em uma mesma matriz/ordem discursiva. Não há por que abordarmos uma se a segunda não estivesse determinando as condições para a existência da primeira. Compartilho, nesse sentido, as idéias de Foucault (1996) quando afirma que, desde o século XIX, o compromisso das instituições de seqüestro não era o de excluir, mas o de "fixar os indivíduos em um aparelho de normalização dos homens" (p. 114). Ainda nas palavras de Foucault,

A fábrica, a escola, a prisão ou os hospitais têm por objetivo ligar o indivíduo a um processo de produção, de formação ou de correção dos produtores. Tratase de garantir a produção ou os produtores em função de uma determinada norma [...] Trata-se, portanto, de uma inclusão por exclusão. (p. 114) 
Enquanto que a operação de reclusão no século XVIII visava à limpeza pela exclusão dos marginais, no século XIX, objetivava sua inclusão para a correção e para a normalização. Um deslocamento nas formas de ver e de operar sobre a idéia de inclusão se estabelece no século XIX. Forma-se uma rede de instituições de seqüestro onde o estado e o que não é estatal se misturam através de distintos mecanismos de vigilância, de normalização dos indivíduos e de segurança no interior das instituições. Tal rede se estabelece operando sobre os indivíduos através do acompanhamento rigoroso e documentado da ocupação do tempo, do espaço, da economia e do próprio corpo dos indivíduos.

Explicando cada um desses mecanismos, é possível dizer que, imbricados em todas as formas e manifestações de vigilância, estão, entre outras preocupações, a manutenção de fluxos de informações, a preocupação com a determinação, mesmo que provisória, de enquadramentos individuais, sociais, econômicos, culturais e políticos e a inscrição do país na lógica perversa do neoliberalismo e/ou do Império (Hardt y Negri, 2003).

A ocupação e gerência de nosso tempo tornaram-se condição mínima para sermos capturados pela lógica do capitalismo. A necessidade de ampliação do tempo cotidiano -tirando dele o máximo de produtividade- torna-nos capazes de relacionamentos simultâneos que podem render relações e contatos virtuais passageiros e superficiais, visibilidade, inclusão em mais grupos e sustentabilidade. Também nos torna capazes de gerir nosso sustento sem ocuparmos um espaço previamente criado para o trabalho. Produzimos, garantimos a nossa sobrevivência e consumimos sem sair de casa, acontecimento que otimiza o tempo de produção e preenche o tempo da vida. Com o tempo preenchido, mantemo-nos capturados/incluídos nas tramas que garantem os fluxos da informação, do consumo e da produção.

$\mathrm{Na}$ contemporaneidade, a vigilância e o controle do espaço estabelecem-se pela captura do corpo e do tempo dos indivíduos e pela diferença/diferenciação cultural. Em uma operação de distribuição dos indivíduos ou de ordenamento por pertencimento a grupos culturais específicos ou pelo estabelecimento de atribuição e distribuição, pelos especialistas, de diagnósticos que determinam e enquadram, mesmo que provisoriamente, os indivíduos, a governamentalidade dos incluídos e dos excluídos se estabelece. "Desde o século XVIII, vivemos na era da governamentalidade” (Foucault, 1992, p. 292). Condutas, saberes e técnicas vêm se inscrevendo, se (re)atualizando e se (re)significando ao longo da história em cada recorte espacial e temporal. Nos movimentos de deslocamento das práticas de governo, podemos dizer que a sofisticação dos mecanismos de vigilância, de prevenção, de economia, de disciplinamento, etc., acaba se constituindo no encontro das técnicas de dominação do sujeito sobre o outro e das técnicas de dominação do sujeito sobre si mesmo.

Emaranhada na teia da governamentalidade, a inclusão coloca-se como um dispositivo capaz de diminuir o risco social e mobilizar todos aqueles que possuem condições de permanecer na luta pelo reconhecimento da diversidade, pela aproxi- 
mação e redução das diferenças, pela condição de produção do Estado e pela proliferação dos projetos sociais e econômicos. As políticas de inclusão, em particular, as políticas de inclusão escolar, podem ser entendidas como uma das formas de manifestação da governamentalização do Estado moderno. (Veiga-Neto y Lopes, 2007)

O acompanhamento detalhado da economia e dos corpos dos indivíduos, de certa maneira, em nossos tempos, confunde-se. Acompanhar o indivíduo em sua capacidade de sustentabilidade e de empregabilidade implica assegurar o próprio corpo individual e social. Retirar do indivíduo o máximo de sua disponibilidade e produtividade é tarefa que exige do Estado e de cada um, em específico, saúde, normalidade constantemente comprovada, disciplina, circulação por distintos grupos considerados atuais, bem colocados e de sucesso, considerando-se padrões locais e globais e educação individual(ista). Em movimentos que vão de um coletivo organizado em torno de interesses comuns, criados e atualizados ao longo da história de uma comunidade, e de interesses particulares e de lutas pontuais a um individualismo exacerbado em que cada vez mais pedagogias se estabelecem para formar indivíduos competidores e capazes de liderança, estão as muitas iniciativas pela manutenção de espaços coletivos capazes de educar para a vida em sociedade. Nessa tensão do jogo de possibilidades de sermos e de estarmos diante do outro, a discussão da inclusão não vem salvar aqueles que estavam à margem dos espaços escolares e de produtividade, mas envolvê-los de forma, às vezes, perversa.

Inclusão e exclusão, portanto, não são movimentos contraditórios e muito menos operam em operações de descarte. São práticas que agem no interior das relações -e para além das instituições- na definição da normalidade, da normatividade e da normalização. Conforme Veiga-Neto (2006),

Os dispositivos normatizadores são aqueles envolvidos com o estabelecimento das normas, ao passo que os normalizadores [são] aqueles que buscam colocar (todos) sob uma norma já estabelecida e, no limite, sob a faixa de normalidade (já definidos por essa norma) (pp. 35-36).

Normalização é usada por Foucault (2006) para assinalar o normal e o anormal em suas diferentes e diversas formas de expressão. Conforme o autor, a "operação de normalização consistirá em fazer interagir essas diferentes atribuições de normalidade e procurar que as mais desfavoráveis se assemelhem às favoráveis" (p. 83). Dessa forma, o normal torna-se, a partir de uma média arbitrária, a referência fundante tanto para a definição de quem é normal quanto para a definição de quem é anormal. Entre normal e anormal, estão séries de sutis designações que localizam os sujeitos em posições que ora os aproximam de figuras anormais, ora os aproximam de figuras normais -sso dependerá dos fluxos de saberes e de informações daqueles autorizados a dar diagnósticos sobre o comportamento dos indivíduos.

Alfredo Veiga-Neto (2001) escreve que a "inclusão pode ser vista como o primeiro passo numa operação de ordenamento, pois é preciso a aproximação com o 
outro, para que se dê um primeiro (re)conhecimento, para que se estabeleça algum saber, por menor que seja, acerca desse outro" (p. 113). Carlos Skliar (2001), em entrevista para Saraí Schimidt, afirma que os sujeitos são constantemente posicionados como incluídos e excluídos. Nas palavras do autor:

não existe tal oposição, senão uma relação que coloca a exclusão e a inclusão dentro da mesma lógica perversa. Assim, a inclusão -tal como ela tem sido colocada como condição existencial para todas as ordens da vida- constitui, na minha opinião, uma estratégia de controle dos excluídos (p. 33).

Em um outro artigo que escrevi, intitulado O lado perverso da inclusão - a exclusão (Lopes, 2006), afirmo que quem ocupa uma das posições de sujeito consideradas adequadas e almejadas por uma sociedade deseja que o outro esteja em uma posição considerada inadequada. Para poder ser visto como estando do lado de dentro, foi preciso inventar o lado de fora. Posições são inventadas a partir de uma materialidade lida e definida por conjuntos de saberes que possibilitam as condições para que uma realidade/verdade se estabeleça pela linguagem (Wittgenstein, 1979). Ao falarmos de muitas formas sobre a inclusão e a exclusão, as produzimos, inclusive, como processos superficialmente opostos. Implicada aí está a negação de uma idéia de essência que preexista à palavra que, alojada sobre uma superfície, a inventa.

A inclusão como uma invenção da Modernidade é explorada e transformada em meta a ser atingida, acontecimento que a torna uma insustentável, mas necessária, invenção. Insustentável porque serão infindáveis os projetos que necessitarão ser feitos para poder mapear, conhecer e satisfazer as necessidades de todos aqueles ditos e autonomeados em situação de exclusão; insustentável porque não há fim para o acelerado processo de descarte da sociedade de consumo; insustentável porque, na sociedade contemporânea, não há lugar, emprego e condições de vida digna para todos. A inclusão é necessária porque é mobilizadora política e da população; necessária porque permite vigiar a todos e a cada um com mais eficiência e menor custo; necessária porque possibilita manter o país entre os países em situação de desenvolvimento; necessária porque normaliza - naturalizando a presença de todos e diminuindo o investimento da Nação em condições materiais específicas e de formação de profissionais para a participação social e política de cada sujeito; necessária para manter as práticas missionárias dentro de um Estado assistencialista. Enfim, necessária para que a crença na mudança de condição de vida continue mobilizando a população em uma direção minimamente e previamente pensada, embora as muitas lutas em prol do reconhecimento da diferença e da diversidade e em prol de outras formas de organização da vida tentem fundar outros modos de condução dos indivíduos. Portanto, não se trata de não pensarmos sobre aqueles apontados como excluídos e incluídos, mas de pensarmos a diferença e a sociedade. Sociedade, população, comunidade e escola são expressões suficientes que nos permitem discutir 
e pensar sobre aqueles que estão desde sempre aí, mas que estão sendo silenciados a partir dos lugares e não-lugares que ocupam em diferentes tempos e espaços.

Pensando a escola da Modernidade como lugar obrigatório para todos, podemos dizer que discutir a inclusão na escola não passa de uma estratégia redundante. Redundância que tem nos conduzido a apontar aqueles que não estão ocupando as posições de aprendizagem e de desenvolvimento consideradas aceitáveis dentro de princípios de normalidade convencionados e aceitos pela instituição político-educacional. Aqueles considerados anormais, problemáticos e que, de alguma forma, estavam andando às margens de uma pretensa zona de normalidade estão sendo capturados por práticas de normalização que muitas vezes acabam operando para dar visibilidade à incapacidade dos indivíduos de serem normalizados.

Estou querendo mostrar, ao problematizar a complexidade do conceito de inclusão na Modernidade e na contemporaneidade, o quão superficial está sendo a discussão sobre a inclusão, principalmente na academia - lugar que deveria pensar a questão para fazê-la ranger e para que possibilidades de pensar de outras formas se constituíssem. Como uma invenção, a inclusão tornou-se uma potente aliada para políticos e discursos inflamados, militantes e poucos acadêmicos. Lopes (2007) escreve

[...] a invenção da inclusão ganha status de verdade e de realidade quando começa a ser produzida nas narrativas, quando começa a circular em diferentes grupos como uma bandeira de luta, quando começa a ganhar forma de lei, quando começa a desenvolver diferentes mecanismos de vigilância e de controle, enfim, quando começa a produzir dados para alimentar médias estatísticas e fazer probabilidades de gestão do risco [...] (p.16).

Talvez afirmar que in/exclusão sejam partes de uma mesma moeda valha um esclarecimento, ou seja, o de que não torno invisíveis aqueles sujeitos sem acesso à escola, ao trabalho, à saúde e às condições de vida com dignidade. Reconheço a invisibilidade do Estado e a sua incapacidade (talvez também desinteresse) de intervir em tais situações para reverter tamanha injustiça social. O que argumento aqui está inscrito em uma outra ordem, a de estarmos nas universidades produzindo saberes que ajudem a posicionar sujeitos como sendo anormais, loucos, rebeldes, delinqüentes, deficientes, não-aprendentes, com problemas sociais, hiperativos, com déficit de atenção, etc. Os conhecimentos que temos e os que cotidianamente vêm sendo produzidos para darem conta de um universo maior de diferenças não traduzidas estão sendo utilizados para explicar comportamentos tidos como desviantes ou desconhecidos por nós, professores. O uso de normas e códigos clínicos para sintomatizarem os alunos nas escolas está sendo cada vez mais eficiente em inventar novos desafios para a escola. Desafios porque a cada dia um conjunto de comportamentos pode ser enquadrado em diagnósticos cada vez mais frágeis, mas que estão servindo para que 
professores afirmem não estar preparados para atuar com alunos enquadrados em categorias que denomino como ameaçadoras pela anormalidade que representam.

Não sendo aprisionada no corpo nem na identidade (Silva, 2000), a diferença se estabelece nas lutas dentro do campo do currículo. No campo de lutas do currículo, os sujeitos são posicionados a partir de uma correlação de forças forjadas naquele espaço. Atribuímos às pessoas com deficiência, devido ao comprometimento visível no corpo (diversidade), uma alteridade deficiente, enfraquecendo-as nas lutas curriculares pelo direito de se auto-representarem. Colocamos tais sujeitos em uma posição anterior às posições definidas nos embates sociais. Não nos deixamos surpreender, nem mesmo deixamos o tempo das relações determinar as posições.

$\mathrm{Na}$ escola, tempo e espaço -somados às condições limitantes da aprendizagem atribuídas a alguns escolares- também se constituem como categorias definidas e utilizadas para determinar a aprendizagem e as posições ocupadas pelos alunos (Acorsi, 2005). Muitos são os pareceres pedagógicos que mostram tais categorias atuando fortemente na disposição dos sujeitos da aprendizagem. Vejamos alguns excertos dos materiais da pesquisa.

-É um aluno que raramente se concentra nas atividades. Levanta muito do lugar e distrai os colegas com brincadeiras de man gosto. Parece nunca ter vontade de fazer atividade alguma. Se omite sempre diante de seus atos. Gosta muito de chamar atenção e às vezes fala como se tivesse a idade de uma criança bem menor. O seu rendimento é baixo, pois nunca termina as atividades propostas com tempo. Têm dificuldade em atividades físicas, como coordenação ampla, ritmo, equilíbrio e atenção.

- Ele não consegue alcançar os outros, ele está sempre atrás dos outros.

- O C. se distrai com facilidade e não se concentra nas tarefas, com isso, está sempre atrasado.

- Para certas coisas, ele é devagar, custa para copiar do quadro.

- Não acompanha na escola; passou com dificuldade, raciocínio lento.

- Dificuldade de aprendizagem. É um aluno bastante agitado, mas é querido e disponivel.

Diante do lugar de onde a escola enuncia sua posição, quase não há espaço para que o indivíduo deixe aparecer suas diferenças. O tempo escolar é que vai determinar o tempo do sujeito, enunciando para ele como, o que e em qual fase do desenvolvimento determinadas aprendizagens devem acontecer. A esse limite espaço-escola e tempo-desenvolvimento, todos devem ser submetidos para que a média de normalidade seja estabelecida. O tempo escolar é único, e o que pode acontecer na escola é que cada aluno, dentro do período de um ano letivo, aprenda mais rapidamente, mais lentamente ou não aprenda o que é ensinado. Pouco ou nada se flexibiliza quando as variáveis são tempo e aprendizagem. Narrativas como as citadas acima-somadas a 
outras, como novamente ele não atingirá a média esse ano; ele vai passar muito fraco para o próximo ano; ele precisa se tratar com uma psicóloga e toda a turma dele já está na quarta série- trazem enunciados que nos fazem colocar sob estranhamento os discursos que estão produzindo e determinando o olhar dos professores.

Tempo e espaço escolarizados determinam o tempo e o espaço dos indivíduos e se sobrepõem àqueles. $\mathrm{Na}$ busca pelo ordenamento social, esses atravessamentos não só entram como princípios avaliativos -mesmo que não declarados nos pareceres pedagógicos-, como também determinam pedagogias que irão operar sobre os indivíduos.

Varela (2002), fazendo um estudo arquegenealógico da história da escola moderna, mostra, além de distintas condições de possibilidade para o surgimento da escola como a vemos hoje, também algumas pedagogias marcadamente presentes em alguns momentos da história. Ela destaca três grandes pedagogias: as disciplinares, as corretivas e as psicológicas. Todas elas aparecem na escola contemporânea; às vezes, uma mais fortemente marcada que outras. As três operam sobre os indivíduos para que eles se enquadrem no que é considerado normal em cada lugar e em cada época.

Estratégias de vigilância e de controle parecem marcar as distintas concepções pedagógicas, com a finalidade de tentar dar conta daqueles que a escola da Modernidade não previu e com quem não sabe como trabalhar. Mecanismos sofisticados de vigilância são criados na escola para que cada aluno seja acompanhado dentro de uma microfísica do detalhe. Seu corpo, sua inteligência, seu desenvolvimento sensório-motor, sua aprendizagem em diferentes áreas do saber, sua mobilidade dentro de diferentes grupos são vigiadas cotidianamente. Tal vigilância exige um acompanhamento rigoroso e uma sofisticação nas formas de registrar o que se vê. Dependendo do que se percebe estar ocorrendo com os alunos -qualquer sinal de incorreção detectado após a aplicação de testes e técnicas corretivas-, uma vasta indústria de fármacos é acionada. Nas entrevistas feitas com professores, é recorrente e comum estes fazerem referência a tratamentos, a diagnósticos que eles mesmos dão, mesmo sem ter competência para tanto. Nos excertos das entrevistas, podemos ler:

- Já tentamos tudo que podíamos na escola, a família não assume, ele continua cada vez pior. Ninguém pode com ele. Ele tem um problema que precisa ser tratado por neurologista. Já tive um aluno parecido com ele que demorou para descobrirmos que ele tinha hiperatividade. Quando começou a tomar Ritalina, foi uma beleza.

- Na minha época, essas crianças que ninguém pode com a vida delas tomavam Gardenal, mas hoje parece que esses remédios não fazem mais efeito, porque, de inquietos, eles passam para desatentos, sonolentos na aula. - Eu disse para a supervisora e para a família que ele tem problemas e precisa tomar um remédio. Parece que o médico já receitou alguma coisa para ele, mas a família não dá direito o remédio. 
As muitas estratégias de controle vistas em operação nas escolas, principalmente quando casos de alunos ditos problemas não conseguem ser resolvidos, são dispendiosas para o Estado, que necessita ter políticas educacionais desenvolvidas e serviços de atendimento para todos aqueles que precisam ser atendidos no campo da saúde. Os alunos que não são capturados pelas redes disciplinares são potenciais pacientes para os postos de saúde. Os professores que não conseguem dar conta da educação dos seus alunos são chamados a darem retorno e a darem justificativas pela não-aprendizagem dos alunos; os gestores das escolas, quando o número de alunos reprovados aumenta, são chamados pelas Secretarias de Ensino do Estado ou do Município a prestarem justificativas sobre o que pode estar acontecendo na escola. Todos esses movimentos de vigilância e de controle podem ser interpretados como estratégias de manutenção do sucesso do grande projeto de inclusão forjado ao longo da Modernidade.

Independentemente das concepções pedagógicas que se instalem nas escolas de hoje, elas são distintas, porém, em certa medida, não são excludentes uma da outra. É possível afirmar que elas funcionam em uma simbiose que tem como princípio organizador a disciplina do sujeito e, por conseqüência, a manutenção, a educação e o ordenamento do coletivo. Kant (1996) enunciava a disciplina como uma condição necessária para o desenvolvimento, atribuindo à escola a tarefa de disciplinar mais do que de ensinar conteúdos específicos. Na ótica kantiana e da escola Moderna, cabe à escola a formação de um coletivo que possa estar tocando projetos sociais com responsabilidade e consciência; para tanto, a disciplina torna-se essencial, visto que cada indivíduo, ao sujeitar-se às regras sociais, deve comportar-se conforme o que é esperado dele.

É interessante observar que, em grande parte dos pareceres pedagógicos, após uma breve citação de não-aprendizagem da leitura e da escrita (geralmente, feita de forma genérica, por exemplo, "ele não lê e não escreve", "ela não sabe ler", "já faz anos que está na primeira série e não lê"), aparecem descritos em detalhes comportamentos que os professores consideram inadequados para um bom desenvolvimento e aprendizagem. Não podendo, por motivos disciplinares, nem ser reprovados nem encaminhados para serviços de apoio pedagógico, os alunos considerados indisciplinados são apontados como tendo dificuldade de aprendizagem. Aquilo que Kant afirmava, no final do século XVIII, ser uma das razões para enviarmos as crianças à escola parece permanecer até nossos dias. Nos excertos dos materiais de pesquisa, podemos observar: 
- Em aula, o aluno é disperso, fala constantemente, mesmo sentado defronte ao professor, não pára de falar, não copia nada, mas, nas provas, vai bem. (...). Se ele recebe algum castigo, ele não liga, para ele, tanto faz, aparentemente nada atinge ele, mas não responde se lhe chamam a atenção.

- Ele não acompanha o ritmo normal e também não consegue adaptar-se a esse ambiente. Mas, com esse projeto onde o processo é mais lento, ele está apresentando resultados.

- Não pára quieto, é agitado e não deixa os colegas trabalharem, mas o médico disse que ele não tem problemas.

- Um aluno que não possui limites. Seu comportamento prejudica o rendimento da turma. Não respeita colegas e professores. O problema com este aluno tem se agravado ao longo dos anos, sem que nenhum avanço seja notado.

O aluno já demonstrou, afirmou que gostaria de deixar a escola.

Atravessamentos culturais, como o silenciamento das vozes no currículo escolar e a incapacidade de a escola tematizar, problematizar e trabalhar com as demandas de hoje, não são questões levantadas como possíveis causas para a não-aprendizagem ou para o comportamento apontado como sendo inadequado em sala de aula.

Olhando para o entorno da escola, para as relações que são estabelecidas dentro dela e para o que os professores narram de seus alunos, podemos dizer que a dificuldade de aprendizagem é uma invenção geral/genérica o suficiente para abarcar a todos. Pelo seu caráter de abrangência, a dificuldade de aprendizagem se torna um diagnóstico poderoso no sentido de sua intraduzibilidade diagnóstica e sua intraduzibilidade pedagógica. Permanecem na categoria alunos com dificuldade de aprendizagem somente aqueles para quem a escola não encontra razões para justificar a não-aprendizagem. Em todos os casos analisados, não foi possível ver qualquer sinalização dos professores que pudessem remeter a questões de ordem cultural e social para justificar a não-aprendizagem dos alunos. Todas as narrativas analisadas justificam o encaminhamento dos alunos afirmando que são eles os responsáveis, juntamente com as famílias, pelos problemas apresentados na escola. Centrar no sujeito a aprendizagem, como se esse fosse o único responsável para que ela se efetive na escola, dificulta aos professores o exercício de uma hipercrítica (Veiga-Neto, 1995). Isso os torna incapazes de suspeitar das verdades que estão circulando no currículo escolar.

Como um dos exemplos maiores de centralização da responsabilidade no indivíduo por sua não-aprendizagem e pelo seu comportamento indesejado, é possível citar a atribuição, pelos professores, de sintomas de TDAH aos alunos. Mesmo sem ter conhecimentos suficientes para diagnosticar dentro do campo clínico e psicológico, os professores utilizam diagnósticos para descrever seus alunos tanto para os pais, quanto para os pesquisadores que circulam na escola. Saberes clínicos circulam entre os professores, e o pouco aprofundamento de saberes dentro do campo da 
educação acaba determinando pedagogias corretivas e encaminhamentos de alunos para especialistas, que são cada vez mais requisitados por aqueles que não estão conseguindo educar os alunos de nosso tempo. Fragmentos das entrevistas que fizemos mostram o pouco cuidado dos professores ao usarem saberes clínicos para escrever pareceres sobre seus alunos e para descrevê-los.

- Ela é uma criança depressiva, desatenta e muito nervosa. Ela deve ter déficit de atenção.

- A mãe corre para que ele venha para a escola, estude e passe de ano, mas ele não quer saber de nada. Anda o tempo todo pela sala, faz um milhão de coisas ao mesmo tempo, é agitado, às vezes, bate nos colegas. Eu disse para a mãe que ele deve ser hiperativo.

- Não gosto nem de pensar que ele possa ser meu aluno no ano que vem. Ele tem Transtorno de Atenção, mas não é tratado. O médico disse que ele não precisa tomar remédio.

Conforme Rohde, Barbosa, Tramontina y Polanczyk (2000), em artigo publicado na Revista Brasileira de Psiquiatria, as primeiras referências ao que se denomina na literatura médica de transtornos hipercinéticos surgiram em meados do século XIX. As formas de nomear tais transtornos vêm sofrendo alterações ao longo dos anos. Na década de 40 do século XX, eram chamados de lesões cerebrais mínimas; na década de 60 , devido às pesquisas mostrarem a fragilidade dos argumentos para sustentar a noção de lesão cerebral, a definição passou a se dar por uma perspectiva mais funcional, marcada pela sindrome de conduta. Tal sindrome da conduta ou a disfunção social mínima, como também é chamada, segundo os especialistas, pode acompanhar o indivíduo a longo de sua vida. Na década de 80, com a continuidade das pesquisas e com a regularidade que os sintomas começaram a aparecer, principalmente apontados pelas escolas, passaram a ser associados aspectos cognitivos à Síndrome. A Síndrome é hoje uma doença reconhecida pela Organização Mundial da Saúde (OMS) e possui, em muitos países, leis de proteção e assistência às pessoas que a possuem, bem como aos seus familiares.

A atualização dos conhecimentos e das formas de nomear um conjunto de comportamentos observados, principalmente em indivíduos que se encontram em idade escolar, exige uma revisão crítica das formas com que diagnósticos atuais de Transtornos de Déficits de Atenção têm sido atribuídos às crianças e aos adolescentes. Há muitas controvérsias entre os especialistas sobre as inúmeras formas de tratar as pessoas com TDAH. Alguns apostam em medicamentos, e outros, por a considerarem como um transtorno social, acreditam que os indivíduos que a possuem devem aprender a conviver com os sintomas, sem medicamentos que os suavizem.

O diagnóstico de TDAH é clínico. Embora muitas discussões e discordâncias existam no campo clínico, conforme as normas classificatórias para que possamos 
detectar sintomas de hiperatividade, é necessário que o indivíduo apresente no mínimo seis sintomas de desatenção ou de hiperatividade, podendo variar no caso de este ser criança, adolescente ou adulto. Além disso, deve apresentar os sintomas por um tempo aproximado de seis meses e em lugares distintos. Nesse conjunto de sintomas, o que é mais preocupante e considerado é o grau de prejuízos que causam no desenvolvimento do indivíduo.

Crianças consideradas sem limites, que apresentam comportamentos típicos de grupos culturais específicos, agitadas, tímidas, distraídas, que apresentam falta de atenção, que não se enquadram no perfil desejado de aluno, etc parecem estar fadadas ao diagnóstico de TDAH ou outro qualquer onde tais comportamentos comuns possam transformar-se em sintomas. Hoje, os alunos não são mais tímidos, nem mesmo podem estar tristes, pois são logo traduzidos dentro de um vocabulário clínico como depressivos. Os alunos não são indisciplinados e agitados, mas hiperativos. Talvez o que salve alguns dos alunos de tais enquadramentos seja o fato de eles não chegarem a prejudicar a rotina e o disciplinamento escolar.

Ter TDAH parece ser algo comum e freqüente em nossas escolas. A recorrência e a facilidade de diagnóstico já são elementos suficientes para suspeitarmos do imenso número de alunos que hoje estão tomando medicamentos que agem diretamente no sistema nervoso central para poderem ser contidos, principalmente, nos horários em que estão na escola. Classicamente caracterizadas como desatentas, hiperativas e impulsivas, as crianças que apresentam tais sintomas, independentemente do nível de inscrição destes no sistema nervoso de cada uma, têm sido facilmente apontadas em escolas e pelas famílias como tendo TDAH.

A descrição feita pelos professores dos comportamentos dos alunos mostra o quanto o saber pedagógico está atravessado por saberes biológicos, psicológicos e psiquiátricos. O vocabulário utilizado para descrever os comportamentos dos alunos é muito semelhante ao utilizado pelos médicos. Ao encaminharem alunos para avaliação médica e psicopedagógica, os professores descrevem sintomas que geralmente são confirmados pelos médicos em seus laudos. A família, na maioria das vezes, já atravessada pelas inúmeras narrativas escolares sobre seus filhos, também aprendem a descrevê-los como indisciplinados, agressivos, agitados, com falta de atenção e incapazes de concluir uma atividade que iniciam. Diante desse conjunto de comportamentos apresentados pelos professores e reafirmados pela escola, os médicos vêem-se pressionados a dar diagnósticos e a prescrever substâncias, como o metilfenidato, comercialmente reconhecido como Ritalina.

Considerando a grande variabilidade de sintomas e a dificuldade dos especialistas de enquadrar os indivíduos em um único diagnóstico, surgem matizes como possibilidade de leitura e de definição de algumas variações comportamentais observadas. Podemos encontrar na literatura, no mínimo, três tipos de TDAH. Um primeiro tipo seria o daqueles com predomínio de sintomas de desatenção; um segundo tipo seria o dos que apresentam sintomas de hiperatividade e de impulsivida- 
de; e o terceiro tipo seria o dos indivíduos que apresentam sintomas dos dois tipos anteriores combinados. Especialistas observam que o tipo de TDAH que implica sintomas de desatenção é mais comum no sexo feminino e que, inclusive, é o que acarreta mais prejuízos escolares. Diferentemente dos indivíduos com sintomas do primeiro tipo, aqueles que apresentam sintomas de hiperatividade e impulsividade são mais agressivos. Geralmente, na escola, estes últimos apresentam problemas de socialização devido à rejeição que sofrem dos colegas. Os que se enquadram no tipo combinado de comportamentos estão mais suscetíveis a viver situações de exclusão e, geralmente, nas escolas, são estigmatizados por professores e colegas.

É interessante observar nos documentos da pesquisa que o número de meninos narrados como agitados, sem limites, criativos e inteligentes, embora apresentem dificuldade de aprendizagem, chegam a aproximadamente $70 \%$ de 371 pareceres pedagógicos analisados. As meninas são geralmente descritas como dóceis, amáveis, meigas e esforçadas. Criatividade e inteligência não parecem ser atributos do sexo feminino. Questões culturais, nesses casos citados, marcadamente questões de gênero, não aparecem como sendo causas prováveis para a presença de sintomas observados pelos professores, familiares, psicopedagogos e alguns médicos, como o de TDAH e de dificuldade de aprendizagem.

\section{Estar incluído em posições conhecidas na escola}

Acredito, inspirada em Wittgenstein (1979), que a linguagem é constitutiva das coisas e que, por essa razão, ao falarmos sobre a não-aprendizagem, sobre alunos de inclusão e sobre os alunos problemas, estamos em boa parte produzindo tais sujeitos. Quero chamar a atenção para o deslocamento que proponho nesta análise, ou seja, ao invés de usar as expressões "dificuldade de aprendizagem", uso a expressão “posição de não-aprendizagem” (Lopes \& Fabris, 2005). Dizer que um sujeito está em uma posição de não-aprendizagem é dizer que diferentes atravessamentos, verdades e práticas estão produzindo tal posição; significa dizer também que, tentando olhar e trabalhar com o entorno do sujeito, podemos estar criando outras posições para ele. Entender os acontecimentos escolares a partir da concepção da centralidade da cultura e a constituição do sujeito por distintas tramas discursivas permite que possamos desconfiar de nós mesmos quando narramos e avaliamos o outro. Nessa linha, como já referi ao optar pela expressão posições de sujeitos, estou investindo política e pedagogicamente em uma educação que pode olhar de outras formas para aqueles em posição de não-aprendizagem.

Ao pensarmos no indivíduo moderno como um sujeito assujeitado, o amarramos a posições sociais distintas, passíveis de serem nomeadas, bem como à sua própria condição inventada de não-aprendente. Preso à sua consciência e a categorias estipuladas por diferentes especialistas que são chamados para trabalhar com os escolares, o sujeito assujeita-se aos saberes que, autorizados dentro de um campo de saber científico, o descrevem e o fazem como alguém problemático que merece 
atendimento diferenciado. Com isso, o que se quer é que ele possa aprender conforme aprendem os outros alunos considerados aprendentes. Os modos de objetivação (Foucault, 1995) -ou como o sujeito da educação se torna um objeto a ser estudado e trabalhado- permitiram a construção do indivíduo moderno e a construção das posições sociais que o sujeito ocupa em cada espaço e tempo limitados. Compreender os processos de assujeitamento, problematizando as práticas que o tornam um caso a ser estudado ou trabalhado pedagogicamente, é um desafio que nos possibilita trabalhar dentro de uma concepção de pedagogia em consonância com as produções culturais.

Descentralizar o sujeito para entendê-lo como constituído nas práticas culturais e assujeitado por diferentes práticas sociais leva-nos a falar de identidades passíveis de ser inventadas para e por ele. Essas identidades são produzidas nas diferentes redes de poder e nos diferentes sistemas de significação que estão em ação pelo uso da linguagem. Tais sistemas de significação e de representações culturais multiplicam-se de acordo com as possibilidades lingüísticas de narrá-los (Lopes, 2004). A multiplicação das possibilidades de narrar os sujeitos e de inventá-los de acordo com diferentes grupos culturais produz a multiplicidade de posições que eles podem ocupar. Tais posições estão indissoluvelmente ligadas a identidades, dentro de determinados contextos.

Inspirada em Ian Hacking (2006) e em Foucault (1992), não existe uma linguagem perfeita que possa dar conta das coisas que descreve, mas existe uma linguagem viva, dinâmica, capaz de criar aquilo que descreve. Nessa compreensão, podemos afirmar que construímos pessoas a partir de um intrincado jogo de relações de saberes estabelecidos entre distintos campos e bases epistemológicas. Pessoas que não esperam que os saberes as identifiquem e as tornem alvos fáceis de tradução movimentam-se (im)previsivelmente. Pessoas modificam-se na medida em que nos aproximamos e que falamos delas. Ao nomearmos, ao produzirmos conhecimentos, em especial nas áreas das assim ditas Ciências Humanas, produzimos pessoas.

Ainda conforme Hacking (2006), ao escrever sobre tipos de pessoas, ressalta que não quer cair em uma invenção mágica e nominalista das pessoas. Frisa que os nomes que usamos para falar das pessoas são apenas uma parte da dinâmica da invenção. No caso de tipos específicos de pessoas, não há apenas diagnósticos que classificam e nomeiam, há também as próprias pessoas classificadas, os especialistas que produzem saberes e os utilizam para fazer as classificações, as instituições que colocam em circulação e que detectam sintomas facilmente enquadráveis em algumas classificações, etc. Há um corpo vivo de conhecimentos em movimento sobre as pessoas de quem se quer falar. Portanto, pessoas são inventadas por meio de classificações, outras pessoas, instituições, especialistas, conhecimentos, médias e estatísticas. Nesse arcabouço de entrecruzamentos, aspectos interagem na construção. Diante disso, é fácil afirmar que dar nomes às coisas não traz só uma dinâmica histórica e presente, como também uma dinâmica relacional. 
O aluno problema (com TDAH, Dificuldade de Aprendizagem, entre outros diagnósticos atribuídos, tratados e quantificados), o aluno com deficiência e o então chamado, depois da forte ênfase dada à inclusão escolar, aluno de inclusão nem sempre existiram, por mais que possamos fazer o exercício de tentar reconhecer sintomas já anunciados em outros momentos da história. Eles só passam a existir no momento em que passamos a falar, nomear e a produzir saberes sobre eles.

Diante da necessidade de ordem imposta e perseguida pela Modernidade, precisamos não só diagnosticar, quantificar, nomear, como também conhecer para poder determinar espaços para cada tipo de sujeito. Dedicamo-nos a narrar e a escrever sobre o outro na tentativa de conhecermos e explicitarmos suas condições. Só a partir daí é que se podem encontrar estratégias, dentro da maquinaria escolar, para normalizar, disciplinar, vigiar e controlar os indivíduos. Conhecer para governar é um princípio evidente na escola, principalmente quando usamos registros para informar sobre nossos alunos. Diante da emergência do enquadramento, a diferença não se torna bem-vinda, pois se constitui em uma ameaça à ordem proclamada e desejada. Como um dos princípios estruturantes do caos, a diferença exige que nos deparemos com o desconhecido e com a nossa incapacidade de trabalhar com os sujeitos da educação. A diferença é o que possibilita movimento e mudanças, bem como outros olhares e outras alteridades que não aquelas narradas como sendo deficientes ou problemáticas (Veiga-Neto y Lopes, 2004).

A inclusão na escola tem se limitado à inclusão da diversidade, e não da diferença. Burbules (2003), ao apontar os usos da diferença reduzida à diversidade, mostra-nos que quem aponta "o" diferente o faz baseado naquilo que é convencionado e marcadamente presente no corpo. As representações hegemônicas que criam aquele com problemas de aprendizagem geralmente estão legitimadas por discursos que, no território contestado da educação escolar, possuem melhores condições de articular a produção do diferente. Silva (1999) alerta que a diferença é produzida por relações de poder; tratar o diferente como um sujeito menor envolve situá-lo em uma posição de menor poder. Então, pensar a diferença sob esse ponto de vista coloca-nos questões que devem ser observadas com atenção por quem está interessado em construir outras bases para o ensino, a aprendizagem e o currículo escolar. Ao mencionar outras bases, não estou querendo dizer que possa existir um currículo revolucionário capaz de articular tudo aquilo que dizemos que a escola atual não dá conta. Nem mesmo estou querendo dizer que conseguiremos fazer outros projetos, mais audaciosos ou críticos, que darão conta daqueles com e sobre quem não sabemos trabalhar de modo a promover a aprendizagem escolarizada.

Não há como dar conta da multiplicação de narrativas e de identidades criadas para representar e inventar o outro com quem trabalhamos. A instabilidade e a geração de projetos que visem a resolver questões emergenciais e pontuais são marcas dos tempos em que vivemos. Diante da necessidade de criarmos novos projetos, existe a necessidade de decifrarmos para quem os criamos. Com uma lista infindável 
de sujeitos que circulam entre diagnósticos que inventam fronteiras, posicionando os alunos entre capazes e incapazes, deficientes e não-deficientes, aprendentes e nãoaprendentes, etc., não há possibilidade de atendimento adequado das diferenças. Cotidianamente e momentaneamente, conforme Bauman (2005), a linha de fronteira entre "normalidade e patologia, saúde e doença, desejável e repulsivo, aceito e rejeitado, o comme il faut e o comme il ne faut pas, o dentro e o fora do universo humano" (p. 39) é reinventada e reativada por novos projetos que visam a incluir e atender todos.

\section{Finalizar é preciso}

Não há um caminho único, nem mesmo um caminho que seja dado como definitivo quando falamos em minimizar os efeitos da diferença inventada a partir de categorias derivadas de distintas ordens -cognitivas, emocionais e físicas, entre outras. Não há uma forma certa de fazer, não há a possibilidade de indicar exemplos para serem copiados, não há o lugar de chegada, nem mesmo a pretensão de não haver mais exclusões. Inclusão e exclusão fazem parte de uma mesma regra e da constituição da escola; do mesmo modo, faz parte da constituição da escola a busca de alternativas para incluir aqueles que vamos vendo e fazendo aparecer.

O mega-projeto da inclusão escolar exige pequenos projetos e práticas capazes de gerar conjuntos de possibilidades para que as diferenças não traduzidas sejam decifradas, para que pedagogias sejam criadas para trabalhar com as diferenças e para que práticas de normalização sejam aplicadas visando ao apagamento do que é indesejado na escola. A tentativa da decifração do que é estranho torna-se uma necessidade facilmente percebida nos pareceres pedagógicos, principalmente quando os professores escrevem afirmando já terem tentado outras alternativas para superação daquilo que eles consideram ser um problema de aprendizagem - como referi, sempre decorrente do comportamento e de tempos distintos para que os processos de ensino e de aprendizagem aconteçam.

Aqueles alunos que resistem à padronização dos tempos e das respostas à aprendizagem escolar são vistos como uma ameaça aos projetos de inclusão. Quando a resistência dos alunos aos processos de homogeneização se manifesta, muitos mecanismos de dominação e docilização são acionados; entre eles, os serviços de apoio pedagógico, as clínicas de psicopedagogia e de educação especial e as clínicas integradas por neurologistas, psicólogos e terapeutas de diferentes tipos. Depois de os alunos considerados problemas serem encaminhados para diferentes especialistas -os quais, muitas vezes, atestam hiperatividade, déficit de atenção, dislexia, etc.-, a escola ganha elementos para afirmar que estão no indivíduo e não no sistema escolar os problemas para que a não-aprendizagem aconteça. Justificar a não-aprendizagem por razões alojadas no indivíduo não possibilita que a escola se reveja e repense o que ela vem produzindo através das verdades que circulam no currículo. A atribuição da negação da vontade de normalizar-se ou da incapacidade da normalização 
-e, portanto, de estar incluído com os demais ditos normais- ao indivíduo é um dos lados perversos e excludentes do projeto escola para todos.

Conforme Ewald (2000), "a norma toma agora o seu valor de jogo das posições entre o normal e o anormal ou entre o normal e o patológico" (p. 78). O conceito de norma passa a não mais se declinar apenas com o normal, "mas com normalidade (1868), normalização (1920). Singular inflação normativa que vai atravessar uma multiplicidade de domínios técnicos e econômicos” (p. 80).

Podendo estabelecer relações estreitas entre a idéia de norma com (a)normalidade, torna-se importante dizer que a norma, pelo seu caráter de abrangência e necessidade de criar medida comum para olhar para todos os sujeitos, contém tanto o normal quanto o anormal. O anormal é aquele que obrigatoriamente está na norma. Embora isso pareça estranho, para ser anormal, ou seja, para não estar enquadrado em determinados moldes estipulados como adequados, corretos para uma sociedade e para um determinado espaço, é preciso existir e ser reconhecido como capaz de ser normalizado. Com esse objetivo de normalização, entre outros, surgiram os manicômios, os presídios, os hospitais e as escolas (regulares e especiais). Essa é a lógica que sustenta a inclusão moderna. Precisamos trazer para perto de nós aqueles que são "a" normais para que tenhamos mais certeza de nossa normalidade.

Habitar o terreno móvel entre aquilo que inventamos ser o lado de dentro (inclusão) e o lado de fora (exclusão) é vivermos constantemente sendo guiados por uma norma (in)visível capaz de regular a todos. Tanto incluídos quanto excluídos precisam estar entre os educados e, após a obrigatoriedade da escola, precisam estar entre os escolarizados.

Entre aqueles que a escola, através de seus professores, vai produzindo como uma ameaça para o projeto da inclusão, podemos apontar, inspirada na classificação de Arnold (2006) -pesquisadora que participou da pesquisa aqui apresentada-, três grupos de alunos: os alunos a corrigir que apresentam dificuldades momentâneas, os alunos em situação de corrigibilidade ou insuficientes, os alunos a corrigir beirando a incorreção ou incorrigíveis.

- os alunos a corrigir que apresentam dificuldades momentâneas: aqueles que atingem, após alguns encontros com profissionais do serviço de apoio pedagógico ou professores particulares, as exigências escolares para a aprovação. Esse grupo é constituído por um número elevado de alunos que são encaminhados para apoio pedagógico, principalmente em épocas de avaliações escolares. Geralmente, as causas, na opinião dos professores, que estão determinando as dificuldades de aprendizagem desses alunos são a desatenção, a hiperatividade e os problemas comportamentais.

- os alunos em situação de corrigibilidade ou insuficientes: aqueles que, às vezes, não conseguem atingir o mínimo desejado para serem aprovados em um ano 
letivo, mas que, com uma dose de esforço escolar e muito esforço pessoal, conseguem, após terem sido reprovados durante dois ou mais anos consecutivos, ser aprovados para a série seguinte. São esses que, conforme são nomeados, se mantêm em situação permanente de correção. O sufixo "-idade" que acompanha a palavra corrigivel é utilizado aqui para marcar uma forma de estar e permanecer na escola. Esse grupo de alunos é composto por aqueles que estão na escola e que, muitas vezes, seguem sua escolarização até a profissionalização, mas que não avançam escolarmente sem o apoio de especialistas. São aqueles que, na pesquisa, foram denominados dependentes de apoio pedagógico.

Dentro desse grupo, podem ser identificados dois subgrupos de sujeitos: o subgrupo dos alunos dúvida (Dal Igna, 2005) e o subgrupo dos alunos ainda não (Arnold, 2006). Os alunos dúvida são aqueles que os professores não conseguem dizer em que posição se encontram. Às vezes, aprendem rapidamente determinados conteúdos que requerem habilidades específicas; outras vezes, as aprendizagens parecem não ser mantidas. Estas parecem não ser assimiladas e não servem de conhecimento prévio para outras aprendizagens mais complexas. O outro subgrupo, o dos alunos ainda não, é composto pelos sujeitos sobre os quais os professores -conhecedores das dificuldades de aprendizagem destes e dos esforços que muitos deles empreendem na superação das dificuldades-creditam uma futura aprendizagem possível que, mais cedo ou mais tarde, será atingida. No grupo dos alunos em situação de corrigibilidade, é comum ouvir os professores discorrerem sobre os comportamentos e as aprendizagens dos alunos antes e depois de estes iniciarem tratamentos com remédios do tipo Ritalina, entre outros.

- os alunos a corrigir beirando a incorreção ou incorrigíveis: aqueles com reprovações sucessivas, com idade avançada, considerando-se a série de ensino, que não conseguem entender e decodificar os códigos escolares e lingüísticos para poder desencadear as aprendizagens proporcionadas pela e na escola. A manutenção do estado de corrigibilidade, somada à situação de fracassos sucessivos nas atividades e anos de reprovações, transforma esses alunos em um grupo de risco, ou seja, em um grupo que ameaça a exeqüibilidade de uma das propostas e objetivos escolares, a saber, educar a todos de acordo com um padrão de normalidade. Por passarem uma vida escolar na expectativa de serem corrigidos, eles evadem da escola, assumindo para si próprios o ônus social do insucesso escolar. É difícil para a escola, embora seja comum, aceitar a idéia de que um aluno não consegue aprender, principalmente porque hoje ele acaba alimentando estatísticas, cada vez mais temidas pelas escolas, da reprovação e da evasão escolar. 
A dificuldade de aprendizagem não passa de um sintoma material presente em um corpo que necessita ser desvendado, desestranhado ou diagnosticado. Não aprende por quê? Dependendo das razões atribuídas para dificuldade de aprendizagem, são criados movimentos de inclusão ou de exclusão da escola comum. Talvez muitos movimentos de incluir e de excluir o aluno da escola comum sejam posições assumidas pelo corpo de professores a partir da opinião e diagnósticos atribuídos aos sujeitos pelos especialistas. Mas vale lembrar que diagnósticos não devem ser vistos como sentenças que determinem o olhar sobre os sujeitos e sobre sua aprendizagem.

\section{Bibliografía}

ACORSI, R. (2005). O que vamos fazer agora? Uma conversa sobre tempo e espaço de aprendizagem. Monografia de Conclusão de Curso de Especialização em Educação Especial. São Leopoldo: UNISINOS.

Arnold, D. (2006). Dificuldade de aprendizagem, condições de corrigibilidade e escola para todos. Dissertação de mestrado. Universidade do Vale do Rio dos Sinos/UNISINOS. Programa de Pós-Graduação em Educação. São Leopoldo: PPGEDU/UNISINOS.

Bauman, Z. (2005). Vidas desperdiçadas. Rio de Janeiro: Jorge Zahar editor.

Burbules, N. (2003). Uma gramática da diferença: algumas formas de repensar a diferença e a diversidade como tópicas educacionais. In: Antonio Flavio Moreira (Org.): Currículo na contemporaneidade: incertezas e desafios (pp. 159-188). São Paulo: Cortez.

Dal Igna, M. (2005). Há diferença? Relações entre desempenho escolar e gênero. Dissertação de mestrado. Universidade Federal do Rio Grande do Sul/UFRGS. Programa de Pós Graduação em Educação. Porto Alegre: PPGEDU/UFRGS.

Ewald, F. (2000). Foucault, a norma e o Direito. 2. ${ }^{a}$ ed. Lisboa: Veja.

Foucault, M. (1992). As palavras e as coisas. São Paulo: Martins Fontes.

Foucault, M. (1995). O sujeito e o poder. In: H. Dreyfus y P. Rabinow. Michel Foucault uma trajetória filosófica para além do estruturalismo e da hermenêutica (pp. 229-254). Rio de Janeiro: Forense.

Foucault, M. (1996). A verdade e as formas jurídicas. Rio de Janeiro: NAU.

Foucault, M. (2006). Seguridad, territorio e población. Buenos Aires: Fondo de Cultura Económica.

KANT, I. (1996). Sobre a Pedagogia. Piracicaba: UNIMEP. 
LOPES, M. (2004). A natureza educável do surdo. In: A. Thoma y M. Lopes (Org.). A invenção da surdez: cultura, alteridade, identidade e diferença no campo da educação (pp. 33-54). Santa Cruz do Sul: EDUNISC.

Lopes, M. y Fabris, E. (2005). Dificuldade de aprendizagem: uma invenção moderna. In: Anais da XXVII Reunião Anual da Associação Nacional de Pesquisa em Educação/ANPED (pp. 1-16). Caxambu: ANPED.

LOPES, M. (2006). O lado perverso da inclusão - a exclusão. In: A. Fávero; C. Dalbosco y T. Marcon. Sobre filosofia e educação: racionalidade e tolerância (pp. 207-218). Passo Fundo/RS: UPF ed. 207.

LOPES, M. (2007). Inclusão escolar: currículo, diferença e identidade. In: M. Lopes y M. Dal Igna. (Org.). In/exclusão nas tramas da escola (pp.11-34). Canoas: ULBRA.

HACKING, I. (2006, abril). Kinds of people: moving targets. Conference presented in The British Academy, London, England.

Hardt, M. y Negri, A. (2003). Império. Río de Janeiro: Record.

Rohde, L.; Barbosa, G.; Tramontina, S. y PolanczyK, G. (2000). Transtorno de Déficit de Atenção/ Hiperatividade. Revista Brasileira de Psiquiatria. São Paulo, 22, 7-11.
SiLva, T. (1999). Documento de identidade. Belo Horizonte: Autêntica.

SILVA, T. (2000). A produção social da identidade e da diferença. In T. Silva (Org.) Identidade e diferença (pp. 190207). Petrópolis: Vozes.

Skliar, C.; Schimidt, S. y Baptista, C. (2001). Inclusão ou exclusão. In: S. Schimidt (Org). A educação em tempos de globalização (pp. 31-40). Río de Janeiro: DP\&A.

VARELA, J. (2002). Categorias espaço temporais: do individualismo ao narcisismo. In: M. Costa (Org). Escola básica na virada do século. Cultura, política e currículo. 3. ${ }^{\mathrm{a}}$ ed. (pp. 73106). São Paulo: Cortez.

Veiga-Neto, A. (1995). Michel Foucault e educação: Há algo de novo sob o sol? In: A. Veiga-Neto (Org). Crítica pós-estruturalista e educação (pp. 9-56). Porto Alegre: Sulina.

Veiga-Neto, A. (2001). Incluir para excluir. In: J. Larrosa y C. Skliar (Org.). Habitantes de Babel: políticas e poéticas da diferença (pp. 105-118). Belo Horizonte: Autêntica.

Veiga-Neto, A. (2006). Dominação, violência, poder e educação escolar em tempos de Império. In M. Rago y A. Veiga-Neto. (Org.). Figuras de Foucault (pp. 13-38). Belo Horizonte: Autêntica.

Veiga-Neto, A. y Lopes, M. (2004). Os meninos. In Educação e Realidade, 1, (29), 229-239. 
Veiga-Neto, A. y Lopes, M. (2007). Inclusão e governamentalidade. In: Educação \& Sociedade, 100, (28), 947-964.
Wittgenstein, L. (1979). Investigações Filosóficas. Série Os Pensadores: Wittgenstein. São Paulo: Abril Cultural e Industrial. 